those of the pre-War years 1911-1913, but rather an upward tendency in the catches during more recent years. It was felt that an increase in the general size limit would entail an immediate loss of a serious nature to a section of the fishermen. As to the destruction of soft crabs, conditions are so different that if more legislation were necessary, close seasons would be different for different areas. It is, moreover, in the power of local fisheries committees to make byelaws imposing further restrictions on the taking of crabs.

It is recommended that further inquiry into the migratory movements of the crab be pursued, and special attention is directed to the experiments on the growth of the lobster at present being carried on at the Scottish Marine Biological Station at Millport. It is anticipated that much light on the life-history of the lobster will result from this work.

Appendices containing the various statisties, with bibliographies of literature relating to crabs and lobsters, are included in the report.

\section{The Law and Practice of Treasure-Trove.}

THE law of treasure-trove has been so ill-defined 1 in the minds of most working archæologists that we welcome the announcement made in the Museum Journal for April, to the effect that negotiations on the subject, which have been in progress for several years between H.M. Treasury and the British Museum, have been brought to a satisfactory conclusion. The decisions of the negotiators have been embodied in a circular, which, as defining the rights of the finder as well as his obligations, deserves the widest publicity. The circular, of which copies may be obtained on application to the Director, British Museum, W.C.I, is as follows: "Objects of gold or silver which have been hidden in the soil or in buildings, and of which the original owner cannot be traced, are Treasure-Trove, and by law the property of the Crown. (Unless-as in some rare cases-the "franchise of Treasure-Trove" has been expressly granted to a subject, in so far as finds in the particular locality are concerned.) If, however, the finder of such objects reports the find promptly, and it is decided that it is Treasure-Trove and therefore the property of the Crown, he will receive its full market value if it is retained for the Crown or a museum. If it is not retained, he will receive back the objects themselves, with full liberty to do what he likes with them; or, if he wishes it, the British Museum will sell them for him at the best price obtainable. The only way in which a finder can comply with the law and also obtain these advantages is by reporting the find promptly to the proper authority.

"The proper authority is the Coroner for the district in which the find is made, for he is the authority who inquires 'of treasure that is found' and 'who were the finders'. (Coroners Act, 1887, section 36.)

"Anyone, therefore, who finds such objects should report the find to the Coroner, either direct or through the local police, or by writing to the Director, British Museum, London, W.C.1, who will communicate with the Coroner.

"Coins and other ancient objects of copper, bronze, or any metal other than gold or silver are not TreasureTrove and finds need not be reported to Coroners. But the British Museum is glad to hear of such finds and, if finds are reported to the Director, will in suitable cases arrange for purchase or sale.

"Any further information may be obtained by applying to the Director, British Museum, London, W.C.1."

No. 3208 , VoL. 127]

\section{Symbiosis and Specificity in Lichens.}

$\mathrm{TN}$ an address at the meeting last year of the Swiss Society of Naturalists (Verhandlungen der Schweizerischen Naturforschenden Gesellschaft, 1930), Chodat gives an interesting survey of the history and recent advances in lichenology. As lichens are the only plants which, as a class, are characterised by a dual nature, they are the outstanding examples of symbiosis - a term first used by De Bary, by which he did not intend to convey any idea of mutual effect of one symbiont upon the other, either for mutual benefit or the reverse.

It has usually been considered that in lichens there is a mutual effect and that this is more marked in the case of the fungus than in that of the alga, for the fungus can seldom, if ever, be ascribed to the same species as any free living form, whilst in many cases the alga has been identified as belonging to some common species. According to some of the earlier workers such as Schwendener, the specificity of the lichen was regarded as due to the fungus constituent, the algal gonidia in such different lichens as Cladonia spp., Xanthoria parietina, and Parmelia spp. all belonging to the one species, Cystococcus humicola.

The recent work of Chodat and his co-workers and of Waren has shown that the algal gonidia cannot be ascribed so readily to free living species as was previously thought. The conception has been shown clearly by pure culture work, from which it emerges that although the gonidia of various lichens may be of the same general type, for example, Cystococcus, those isolated from different species of a lichen genus, for example, Cladonia, are not identical with one another or with the free living forms, and often behave so differently in culture as to be recognisable by the macroscopic form of the colony. It has further been shown by Jaag that similar differences can be recognised between the gonidia isolated from different species of Parmelia, and it is especially interesting to find that the different types of Cystococcus isolated from Parmelia are more like one another than they are to the types of Cystococcus isolated from Cladonia species.

These facts are a little difficult to interpret and Chodat probably deals with the problem in the simplest way by regarding such different types of gonidial algæ as elementary species. Their identification suggests that the building up of a lichen is by no means hap. hazard, but that it involves the coming together of a definite species of a fungus with a particular type or elementary species of alga, and only with this one combination will a lichen of a particular species be synthesised.

\section{Fatigue of Spring Steels.}

CONSIDERABLE trouble has been experienced by the failure in service of aero-engine valve springs. A paper by Swan, Sutton, and Douglas, read before the Institution of Mechanical Engineers on Feb. 20, records an excellent piece of work on the factors which are involved.

The fractures, which were typical of fatigue failure, are ascribed to the stresses set up by 'surging ' superposed on the already highly stressed wire, and were in many cases initiated as a result of some slight surface defect. Most of the wires showed surface decarburisation, and the removal of this layer resulted in an appreciable increase in the safe range of stress. Further, the temperature of quenching exerted a marked influence, and where this was high, longitudinal cracks were formed which resulted in premature failure. 